\title{
Low Expression of Toll-like Receptor 4 Is Associated With Poor Prognosis in Bladder Cancer
}

\author{
YOSHITO KUSUHARA ${ }^{1}$, KEI DAIZUMOTO ${ }^{1}$, KAICHI KAWAI ${ }^{1}$, KENTO HIRAYAMA $^{1}$, MINORU KOWADA ${ }^{1}$, \\ TERUMICHI SHINTANI ${ }^{1}$, YAYOI FUKUHARA ${ }^{1}$, TSOGT-OCHIR DONDOO $^{1}$, KEISUKE OZAKI $^{1}$, \\ MEGUMI TSUDA ${ }^{1}$, TOMOYA FUKAWA ${ }^{1}$, HIROYOSHI NAKATSUJI ${ }^{1}$, YOSHIMI BANDO ${ }^{2}$, \\ HISANORI UEHARA ${ }^{2}$, TOMOHARU FUKUMORI ${ }^{1}$, MASAYUKI TAKAHASHI ${ }^{1}$ and HIRO-OMI KANAYAMA ${ }^{1}$ \\ ${ }^{1}$ Department of Urology, Tokushima University Graduate School of Biomedical Sciences, Tokushima, Japan; \\ ${ }^{2}$ Division of Pathology, Tokushima University Hospital, Tokushima, Japan
}

\begin{abstract}
Background/Aim: The aim of this study was to elucidate the relationship between the progression of bladder cancer (BCa) and TLR4 expression. Materials and Methods: The relationship between TLR4 expression and prognosis of $B C a$ patients was analyzed using a publicly available database and immunohistochemical staining of clinical samples. The effect of TLR4 knockdown was also examined on the invasive capabilities of BCa cells. Finally, to investigate the biological function of TLR4, the gene expression profile of TLR4-depleted $B C a$ cells was analyzed by microarray analysis. Results: Expression of TLR4 was inversely associated with prognosis of patients with invasive $B C a$, and depletion of TLR4 significantly enhanced the invasive capability of $B C$ C cells. Gene expression profiling revealed that depletion of TLR4 led to high expression of epithelial differentiation genes. Furthermore, expression of TLR4 was found to be extremely low in areas of squamous differentiation. Conclusion: Low TLR4 expression was correlated with tumor progression.
\end{abstract}

Bladder cancer (BCa) is one of the most common malignancies of the urinary tract worldwide. In 2016, 76,960 new cases of $\mathrm{BCa}$ and 16,390 BCa-related deaths were estimated in the United States (1). Approximately $30 \%$ of patients with $\mathrm{BCa}$ present with muscle-invasive $\mathrm{BCa}$ (MIBC) (2), however, effective treatments for MIBC have not yet been established. Elucidating the underlying mechanisms of $\mathrm{BCa}$ progression is likely to facilitate the development of new therapeutic approaches to the treatment of MIBC.

Correspondence to: Tomoya Fukawa, Department of Urology, Institute of Biomedical Sciences, Tokushima University Graduate School, 3-18 Kuramoto, Tokushima 770-8503, Japan. Tel: +81 886337159, Fax: +81 886337160, e-mail: fukawa.tomoya@tokushima-u.ac.jp

Key Words: Bladder cancer, Toll-like receptor 4, squamous differentiation.
Many gene mutations are involved in the development of $\mathrm{BCa}$, and $\mathrm{BCa}$ is thought to be an immunogenic tumor (3). Though various kinds of immune cells are induced via recognition of these tumor neoantigens, $\mathrm{BCa}$ cells skillfully survive attacks from these cells and further develop. While inflammation driven from tumor-specific immune reaction can suppress cancer development, noncancer specific inflammation may even boost cancer cell proliferation (4).

Toll-like receptors (TLRs) are involved in inflammatory cytokine production and are expressed in a variety of epithelial and cancer cells (5-7). More than 10 human TLRs have been identified, and current evidence indicates that the TLR signaling cascade is functionally associated with tumor growth, progression, and invasion (8). Previous studies have reported that TLR expression levels differ between cancer types $(9,10)$, and in $\mathrm{BCa}$, Olbert et al. showed the potential involvement of TLR-dependent immune responses in BCa progression (11). However, the precise role of TLRs in BCa pathology remain unclear.

This study, aimed to clarify the contribution of TLRs, especially TLR4, expression to BCa progression and analyze its function, using a panel of human BCa cell lines.

\section{Materials and Methods}

Cell lines and patient specimens. UM-UC-3, 5637, J82 and T24 cell lines were obtained from the American Type Culture Collection (ATCC, Manassas, VA, USA). RT112 was purchased from Cosmo Bio Co. (Japan). All cells were cultured as recommended by respective sources. A total of 95 patients with $\mathrm{BCa}$ diagnosed and operated (transurethral bladder tumor resection) at Tokushima University hospital. Surgically resected patient samples and their clinicopathological information were acquired from Tokushima University Hospital (Tokushima, Japan) after obtaining written informed consent. This study and the use of all clinical materials described above were approved by the ethical review board of Tokushima University Hospital (permission number 709). 
Immunohistochemical analysis (IHC). Sections of paraffinembedded $\mathrm{BCa}$ tissue were deparaffinized in xylene and then rehydrated in a graded ethyl alcohol series $(100 \%, 95 \%$, and $90 \%)$, before being incubated for antigen retrieval using citrate buffer (10 $\mathrm{nM}, \mathrm{pH} 6.0$ ) for $10 \mathrm{~min}$. To increase specificity and sensitivity, tissues were autoclaved for $10 \mathrm{~min}$ to retrieve antigen. After cooling and rinsing in distilled water, endogenous peroxide activity was blocked with $3 \% \mathrm{H}_{2} \mathrm{O}_{2}$ for $10 \mathrm{~min}$. Then, samples were rinsed in $0.01 \mathrm{~mol} / 1 \mathrm{phosphate-buffered} \mathrm{saline} \mathrm{(PBS,} \mathrm{pH} 7.4$ ) for $10 \mathrm{~min}$ and pre-incubated with a protein blocking solution for $5 \mathrm{~min}$. Sections were incubated with a mouse monoclonal antibody against TLR4 (Abcam, ab22048; diluted 1:200 in PBS) overnight at $4^{\circ} \mathrm{C}$. They were then washed three times in PBS and incubated with Dako REAL $^{\mathrm{TM}}$ EnVision ${ }^{\mathrm{TM}} / \mathrm{HRP}$, Rabbit/Mouse (DAKO) 1-2 drops for 1 $\mathrm{h}$ at room temperature, before being again washed with PBS and incubated with diaminobenzidine (DAB) and substrate chromogen system for $5 \mathrm{~min}$ at room temperature, which resulted in brown colored precipitates at the antigen site. Sections were then counterstained with hematoxylin for $1 \mathrm{~min}$ and mounted. Sections with more than $10 \%$ positive cancer cells were regarded as positive samples.

Evaluation of immunostaining. Three researchers, blinded to clinical features and outcomes, evaluated each slide independently. The IHC expression intensity of TLR4 was scored on a scale of 0 (no staining), 1 (low), 2 (intermediate) and 3 (high), and the percentage of TLR4 positive cells was also evaluated. Multiplication of the TLR4 intensity score and percentage was used to divide patients into two groups for outcome analysis (values $\leq 60$ representing lowexpression, and $>60$ representing high expression).

Quantitative and semi-quantitative reverse transcription-PCR. Total RNA was extracted from cultured cells using the RNeasy Mini Kit (QIAGEN, Valencia, CA, USA) as previously described (12). We prepared the appropriate dilutions of each single-stranded cDNA for subsequent PCR amplification and monitored reactions using $\beta$-actin as a quantitative control. Each sample was analyzed in triplicate for each primer pair. The relative expression levels of target genes were obtained using Light Cycler Software Ver.3.5 (Roche Diagnostics, Madison, WI, USA), and calculated using the $2^{-\Delta \Delta \mathrm{Ct}}$ method.

Western blot analysis. Cells were lysed with Mammalian Cell Extraction kit (Bio Vision, Mountain View, CA). After centrifugation at $14,000 \mathrm{~g}$ for $10 \mathrm{~min}$, the supernatant was collected as the total protein extract and stored at $-80^{\circ} \mathrm{C}$ until use. Equal amounts of protein were separated by SDS-PAGE and transferred to a polyvinylidene difluoride membrane. The membrane then was blocked with Block Ace (Dainippon Pharmaceutical, Osaka, Japan) for $60 \mathrm{~min}$ and incubated with anti-TLR4 (Abcam, ab22048, dilution 1:100) or anti- $\beta$-actin (Sigma-Aldrich, A5441, dilution $1: 1,000)$ primary antibodies at $4^{\circ} \mathrm{C}$ overnight. After incubation with an HRP-conjugated secondary antibody (Thermo Fisher Scientific, Waltham, MA, USA, dilution 1:1,000) for $60 \mathrm{~min}$, blots were developed with an enhanced ECL Plus Kit (GE Healthcare, Piscataway, NJ, USA). and scanned using an Image Reader LAS500 (Fujifilm, Tokyo, Japan).

RNA interference. siRNA oligonucleotides were used to knock down TLR4 in bladder cancer cell lines. Non-silencing RNA duplex was used as a negative control. Transfection with $10 \mathrm{nM}$ of each siRNA to each cell line was performed using Lipofectamine RNAiMAX (Thermo Fisher Scientific) with the reverse transfection method.

Microarray analysis. Cyanine-3 (Cy3) labeled cRNA was prepared from 150 ng RNA using the One-Color Low Input Quick Amp Labeling kit (Agilent, Santa Clara, CA, USA) according to the manufacturer's instructions, followed by RNAeasy column purification (QIAGEN). Dye incorporation and cRNA yield were checked with the NanoDrop ND-1000 Spectrophotometer.

The amount of $600 \mathrm{ng}$ of Cy3-labelled cRNA (specific activity $>6$ pmol Cy3/ $\mu$ g cRNA) was fragmented at $60^{\circ} \mathrm{C}$ for $30 \mathrm{~min}$ in a reaction volume of $25 \mu \mathrm{l}$ containing $25 \times$ Agilent fragmentation buffer and 10x Agilent blocking agent following the manufacturer's instructions. On completion of the fragmentation reaction, $25 \mu \mathrm{l}$ of $2 \mathrm{x}$ Agilent hybridization buffer was added to the fragmentation mixture and hybridized to Agilent SurePrint GE Unrestricted Microarrays $(\mathrm{G} 2519 \mathrm{~F})$ for $17 \mathrm{~h}$ at $65^{\circ} \mathrm{C}$ in a rotating Agilent hybridization oven. After hybridization, microarrays were washed 1 minute at room temperature with GE Wash Buffer 1 (Agilent) and 1 min with $37^{\circ} \mathrm{C} \mathrm{GE}$ Wash buffer 2 (Agilent), then dried immediately.

Slides were scanned immediately after washing on the Agilent DNA Microarray Scanner (G2505C) using one color scan setting for $8 \times 60 \mathrm{~K}$ array slides (Scan Area $61 \times 21.6 \mathrm{~mm}$, Scan resolution $3 \mu \mathrm{m}$, Dye channel was set to Green and Green PMT was set to $100 \%$ ).

The scanned images were analyzed with Feature Extraction Software 10.7.1.1 (Agilent) using default parameters (protocol GE1_107_Sep09 and Grid: 028282_D_F_20110531) to obtain background subtracted and spatially detrended processed signal intensities. Features flagged in Feature Extraction as Feature Nonuniform outliers were excluded.

MTT assay. The 5637 cells were seeded into 96-well plates at $1.0 \times 10^{4}$ cells $(100 \mu \mathrm{l})$ per well and maintained in medium containing $10 \%$ fetal bovine serum (FBS). After a 72, 96 and $120 \mathrm{~h}$ incubation, cell proliferation was evaluated using the Cell Counting Kit-8 (Dojindo, Kumamoto, Japan). At the indicated time points, a 1:10 dilution of the CCK- 8 solution was added and incubated for $30 \mathrm{~min}$. Then, the absorbance at $450 \mathrm{~nm}$ was measured to calculate the number of vital cells/well using VARIOSKAN FLASH (Thermo Fisher Scientific).

In vitro invasiveness and migration assays. Invasion and migration assays of 5637 cells, with and without TLR4 expression, were performed using the xCELLigence RTCA Analyzer (Roche Applied Science, Mannheim, Germany) in a humidified atmosphere of $5 \% \mathrm{CO}_{2}$ and $95 \%$ air at $37^{\circ} \mathrm{C}$. Cell invasion and migration (CIM) plates (ACEA Biosciences, San Diego, CA, USA) initially contained cells in transfection solution at a density of $4 \times 10^{4}$ cells per well; this media was replaced with fresh RPMI1640 medium. The lower wells were filled with $160 \mu \mathrm{l}$ of RPMI1640 medium with $10 \%$ FBS. Invasion capability was tested using a tumor invasion system (BD Biosciences, Bedford, MA, USA), in Matrigel diluted 1:40 with RPMI1640 medium (as detailed by Roche in the application notes) coated onto 16-well plates. Measurement of changes in the cell index, which shows cell invasion or migration status based on the measured electrical impedance, were made over time intervals between 0 to $60 \mathrm{~h}$.

Bioinformatic analyses. PrognoScan database (http://www.abren.net/ PrognoScan/) analysis was conducted. The expression levels of TLR genes, SPRRs and keratins were analyzed with the dataset of $\mathrm{BCa}$ 
A

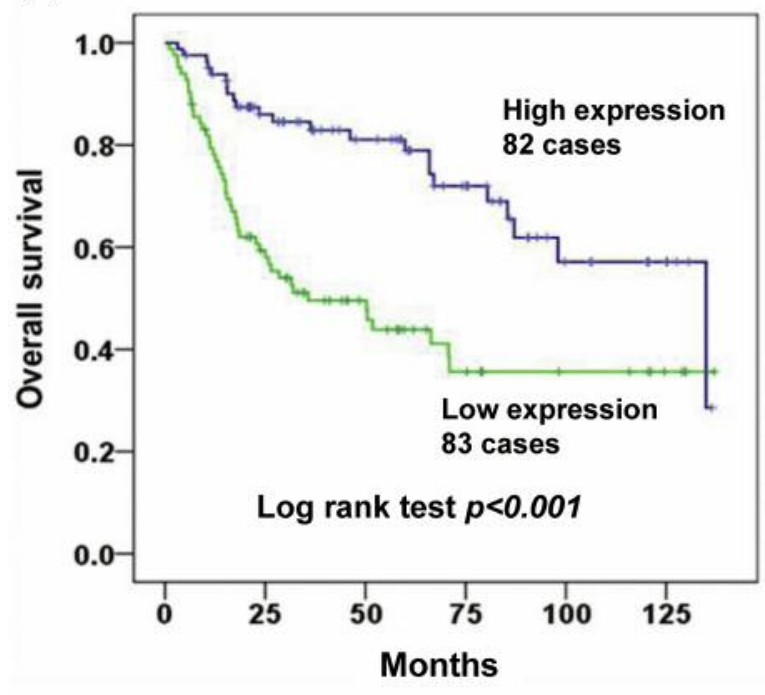

C

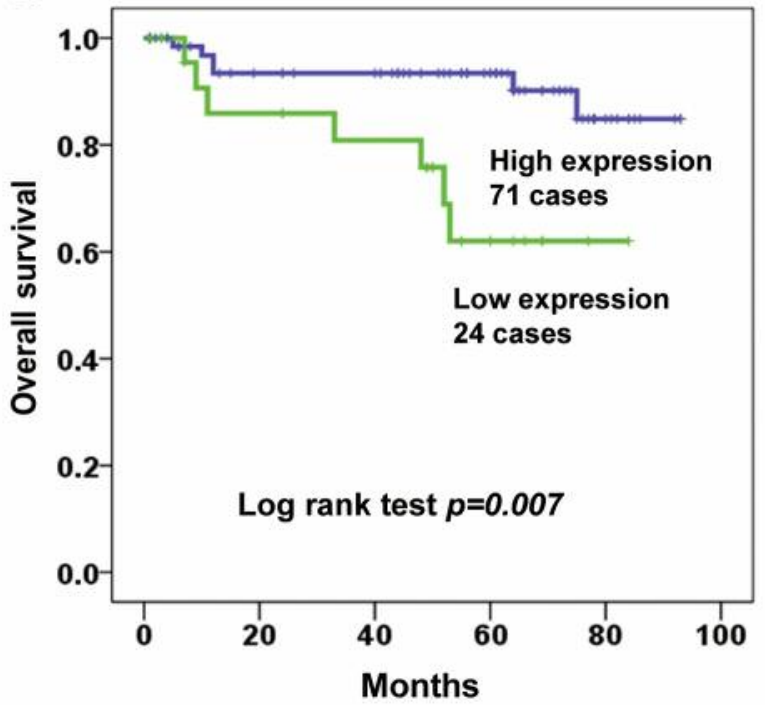

B
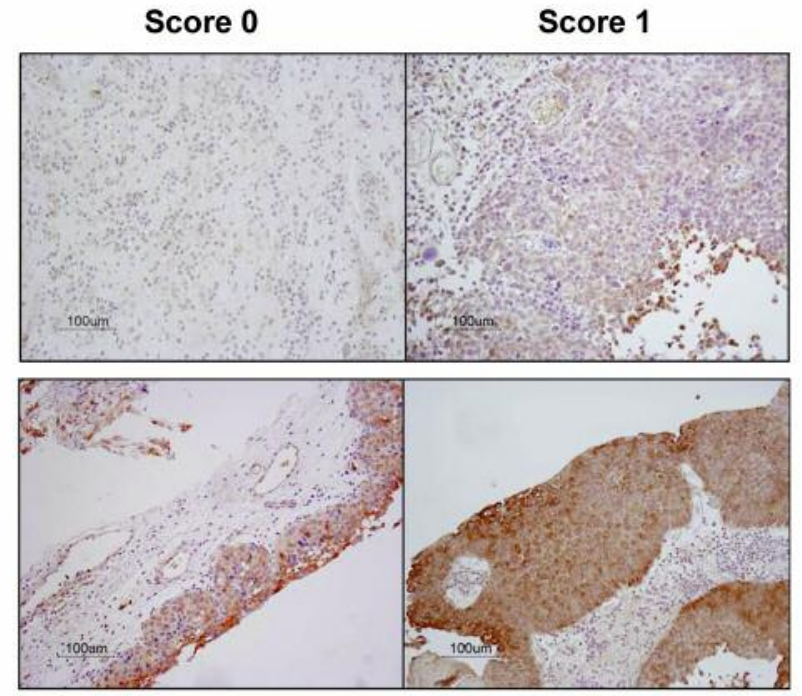

Score 2

Score 3
D

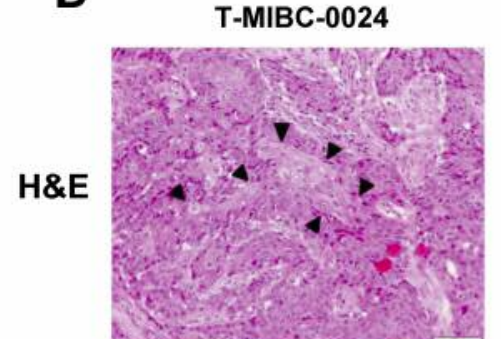

TLR4

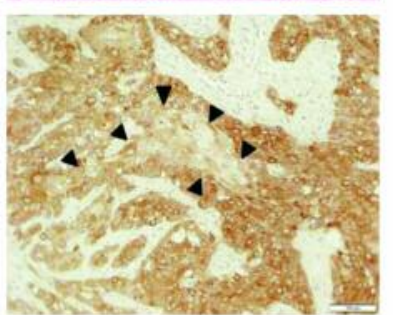

T-MIBC-0047
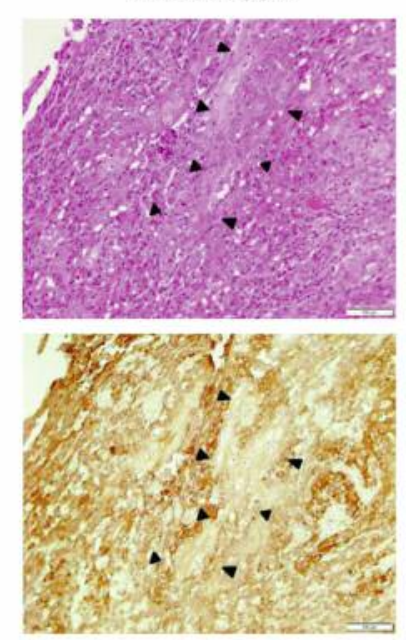

Figure 1. Relationship between TLR4 expression and prognosis of patients with BCa. (A) Kaplan-Meier analysis of overall survival of BCa patients according to TLR4 expression (based on outcome data provided by PrognoScan). (B) IHC with anti-TLR4 antibody, with each image scored from 0 to 3 for expression level. (C) Kaplan-Meier analysis of overall survival of BCa patients according to TLR4 expression. (D) TLR4 expression in TUR specimens by IHC. Arrows indicate areas of squamous differentiation.

patients (GSE 13507). Gene datasets from microarray analyses were submitted to DAVID (Database for Annotation, Visualization, and Integrated Discovery; http://david.abcc.ncifcrf.gov/) to identify significantly enriched biological process $(\mathrm{BP})$, molecular function (MF), and cellular component (CC) terms based on the GO (Gene Ontology) database.

Statistical analysis. Cancer-specific survival curves were estimated using the Kaplan-Meier method, with significance assessed by logrank test. High and low TLR4-expressing patients were defined as those with greater than, or less than the median level of TLR4 expression, as described in the evaluation of immunostaining section, respectively. Cox proportional hazards analysis was used to identify significant prognostic clinical factors and to test for independent contributions to cancer-specific survival. Statistical significance in regard to cell proliferation or gene expression analysis was calculated by Student's $t$-test. Significance levels of $p<0.05\left(^{*}\right)$ and $p<0.001(* *)$ were defined, and analyses were performed with SPSS Statistics ${ }^{\circledR} 25$ (SPSS, IBM Corp, Armonk, NY, USA). 


\section{Results}

Relationship between TLR expression and BCa prognosis. To identify which TLRs might contribute to progression of $\mathrm{BCa}$, the relationship between their levels of expression and prognosis was analyzed using the public database, PrognoScan (http://www.prognoscan.org/). This revealed that low expression of TLR4 was significantly associated with poor prognosis in BCa patients (Figure 1A), and that the relationship was stronger for TLR4 than for any of the other TLRs (Table I).

Clinicopathological characteristics and TLR4 expression in $B C a$. To confirm the relationship between TLR4 expression and prognosis of $\mathrm{BCa}$ patients at the protein level, transurethral resection (TUR) BCa specimens were analyzed by IHC. This analysis confirmed the association with prognosis (Figure 1B, C), and indicated that the expression of TLR4 was significantly associated with $\mathrm{T}$ stage and presence of metastasis (Table II). In addition, IHC staining with an TLR4 antibody revealed that the expression of TLR4 was especially low in areas where squamous differentiation was observed (Figure 1D).

TLR4 expression in BCa cell lines. The expression of TLR4 in $\mathrm{BCa}$ cell lines was analyzed by western blotting. This analysis revealed that three of five BCa cell lines, 5637, RT112 and J82 cells, had relatively high expression of TLR4 (Figure 2A).

To assess whether TLR4 expression might affect cell proliferation or the invasion capability of BCa cells, MTT, invasion and migration assays were performed using cell lines with endogenously high expression of TLR4, with or without depletion of that expression by siRNA knockdown (Figures 2B-F). The results revealed that although knockdown of TLR4 expression suppressed cell growth (Figure 2D), the invasive and migration abilities of $\mathrm{BCa}$ cell lines were dramatically increased in TLR4 depleted cells (Figures 2E, F). Furthermore, the morphology of TLR4-depleted cells changed from a rounded to a polygonal or spindle shape (Figure $2 \mathrm{G}$ ).

Genome-wide analysis of the influence of TLR4 depletion in $B C a$ cells. To elucidate the molecular basis for the observed morphological changes in $\mathrm{BCa}$ cells, the gene expression profiles of the cell lines with/without depletion of TLR4 were compared. GO analysis revealed that many genes functionally involved in epithelial development or differentiation, were dramatically up-regulated in TLR4depleted cells (Table III). Among these genes, the keratins and small proline-rich proteins (SPRRs) were found to be inversely associated with the expression of TLR4 (Figure $3 \mathrm{~A})$. These findings were confirmed using quantitative RTPCR in both 5637 and RT112 BCa cell lines (Figure 3B, C). Finally, the expression of epithelial-mesenchymal transition (EMT)-related genes was examined in these cells. However,
Table I. Relationship between TLRs expression and prognosis of patients with bladder cancer.

\begin{tabular}{lcccc}
\hline $\begin{array}{l}\text { Gene symbol } \\
\text { low } v \text { s. high }\end{array}$ & $\begin{array}{c}\text { Cox } \\
p \text {-Value }\end{array}$ & $\begin{array}{c}\text { Hazard } \\
\text { ratio }\end{array}$ & \multicolumn{2}{c}{ HR } \\
\hline TLR1 & 0.872 & 0.96 & 0.58 & 1.59 \\
TLR2 & 0.22 & 0.43 & 0.11 & 1.66 \\
TLR3 & 0.16 & 0.62 & 0.32 & 1.22 \\
TLR4 & $<0.001$ & 0.15 & 0.06 & 0.39 \\
TLR5 & 0.27 & 1.17 & 0.88 & 1.57 \\
TLR6 & 0.88 & 0.95 & 0.44 & 2.03 \\
TLR7 & 0.32 & 0.75 & 0.43 & 1.32 \\
TLR8 & 0.74 & 0.78 & 0.18 & 3.41 \\
TLR9 & 0.29 & 1.64 & 0.64 & 4.19 \\
TLR10 & 0.03 & 2.22 & 1.04 & 4.74 \\
\hline
\end{tabular}

Table II. Univariate analyses of clinical factors associated with TLR4 expression.

\begin{tabular}{lrrr}
\hline & High & Low & $p$-Value \\
\hline Age & & & \\
$\geq 65$ & 48 & 15 & \\
$65>$ & 23 & 9 & 0.803 \\
Gender & & & \\
Male & 57 & 19 & \\
Female & 14 & 5 & 1 \\
Grade & & & \\
1 or 2 & 41 & 13 & 0.814 \\
3 & 30 & 11 & \\
$\mathrm{~T}$ & & 13 & 0.047 \\
$\leq \mathrm{T} 1$ & 50 & & \\
$\geq \mathrm{T} 2$ & 21 & 21 & 0.688 \\
$\mathrm{~N}$ & & 3 & \\
0 & 65 & 20 & 0.034 \\
1 & 6 & 4 & \\
$\mathrm{M}$ & & & \\
0 & 69 & & \\
1 & 2 & & \\
\hline
\end{tabular}

inconsistent results were obtained regarding the levels of these molecules following TLR4 knockdown (Figure 3D).

To further verify our findings, the association between BCa patient prognosis and expression of keratins and SPRRs was investigated using data from the PrognoScan database. This analysis revealed that high expression of these genes was significantly associated with poor prognosis of patients with BCa (Figure 3E).

\section{Discussion}

In this study, TLR4 was identified as an important molecule in the progression of $\mathrm{BCa}$. This conclusion is based upon four key 
A

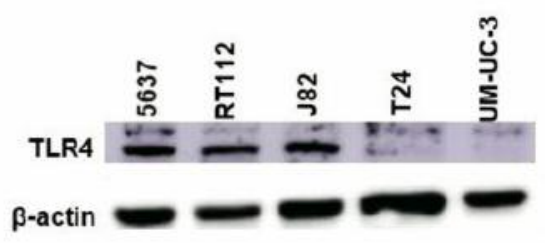

C

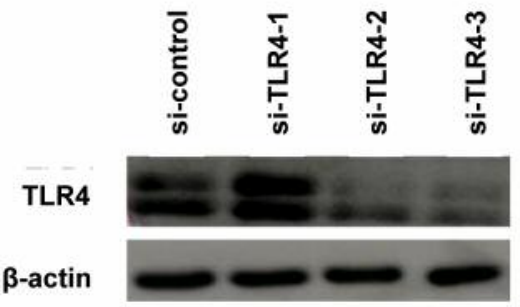

E

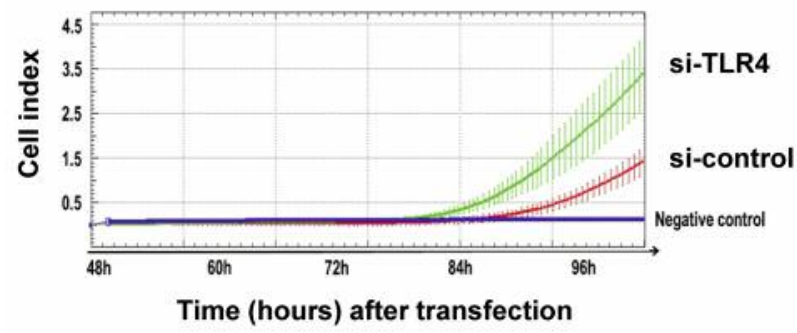

G

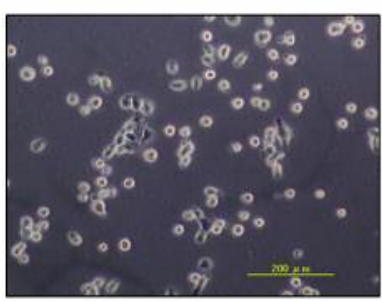

B

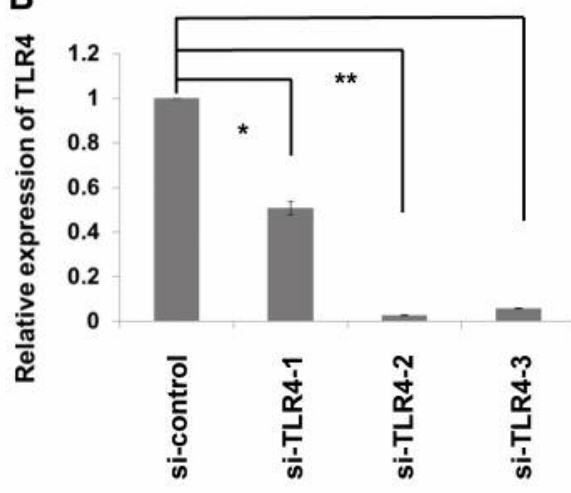

D

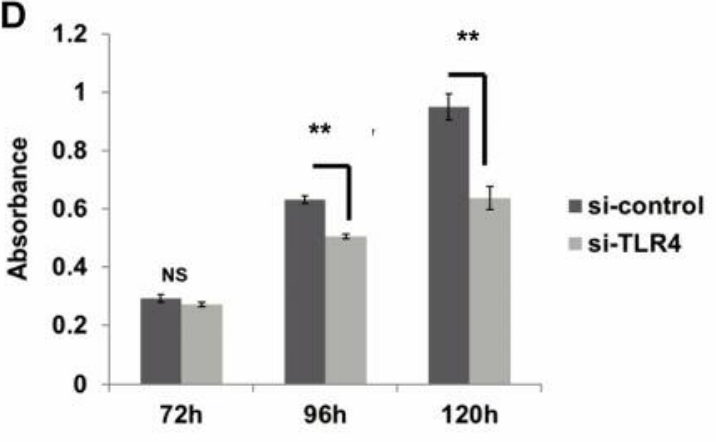

$\mathbf{F}$

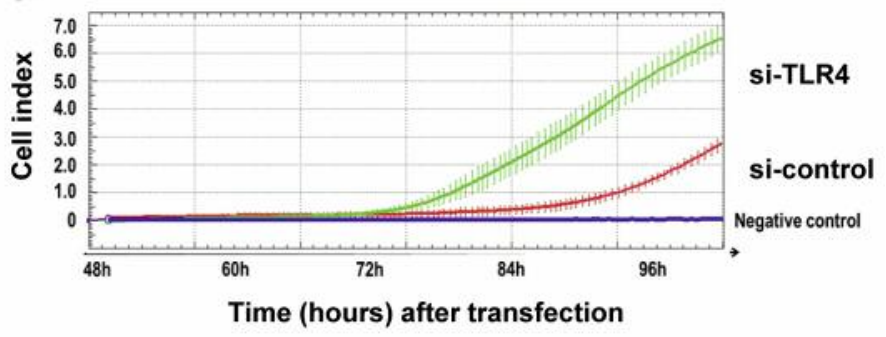

Figure 2. The relationship between expression of TLR4 and cancer cell viability. (A) Western blot analysis of the expression of TLR4 in BCa cell lines. $(B, C)$ Knockdown effects of si-TLR4s at the mRNA level $(B)$ and protein level $(C)$. (D-G) Effect of TLR4 depletion on cell growth $(D)$, invasion $(E)$, migration $(F)$ and cell morphology $(G) . * p<0.05, * * p<0.001$.

findings. First, there was a significant association between low expression of TLR4 and poor clinical outcome in BCa patients. Second, depletion of TLR4 expression in those cell lines enhanced their invasive ability. Third, gene expression profiling revealed that depletion of TLR4 in these low stage BCa cell lines increased the expression of cell morphology related genes, including keratin proteins and SPRRs. Fourth, TLR4 expression was found to be lower in areas of squamous differentiation, suggesting that TLR4 controls squamous differentiation of $\mathrm{BCa}$ by regulating the expressions of keratins and SPRRs. 
Table III. Top-ranking gene set signatures from Gene Ontology (GO) analysis of 5637 cells, after treatment for $72 h$ with siTLR4.

\begin{tabular}{lccc}
\hline & GO term & Fold enrichment & FDR \\
\hline GOTERM_BP_ALL & Epidermis development & 8.1 & 0.0000005 \\
GOTERM_BP_ALL & Ectoderm development & 7.5 & 0.000002 \\
GOTERM_CC_ALL & Cornified envelope & 30.4 & 0.000006 \\
GOTERM_CC_ALL & Extracellular region & 2.2 & 0.00004 \\
GOTERM_BP_ALL & Anatomical structure development & 2 & 0.0001 \\
GOTERM_BP_ALL & System development & 2.1 & 0.0001 \\
GOTERM_CC_ALL & Extracellular region part & 2.9 & 0.0001 \\
GOTERM_BP_ALL & Tissue development & 3.4 & 0.0002 \\
GOTERM_BP_ALL & Developmental process & 1.8 & 0.0002 \\
GOTERM_BP_ALL & Multicellular organismal process & 1.7 & 0.0002 \\
GOTERM_BP_ALL & Multicellular organismal development & 1.9 & 0.0006 \\
GOTERM_CC_ALL & Extracellular space & 3.2 & 0.0008 \\
GOTERM_BP_ALL & Keratinization & 16.3 & 0.0008 \\
GOTERM_MF_ALL & Cytokine activity & 5.9 & 0.003 \\
GOTERM_MF_ALL & Receptor binding & 2.8 & 0.003 \\
GOTERM_BP_ALL & Organ development & 2.1 & 0.005 \\
GOTERM_BP_ALL & Epithelial cell differentiation & 7 & 0.006 \\
GOTERM_BP_ALL & Keratinocyte differentiation & 10.6 & 0.01 \\
GOTERM_BP_ALL & Epidermal cell differentiation & 0.7 \\
\hline
\end{tabular}

It has been reported that TLR4 is expressed in urothelial epithelium (6), especially in response to urinal tract infection (13-16). However, no studies have described the relationship between TLR4 expression and clinical factors, and only a few studies have described the role of TLR4 in BCa. One report showed that a TLR4 polymorphism that results in lower protein expression, contributes to $\mathrm{BCa}$ susceptibility by suppressing the immune system (17), but this report examined the TLR4 expression levels in immune cells rather than in the tumor cells themselves. In our study, IHC staining in TUR specimens revealed that the expression of TLR4 is lower in $\mathrm{BCa}$ tumors associated with poor prognosis which was consistent with the results from Prognoscan data. These results indicated that the association between TLR4 expression and clinical outcome may be related not only to the functional impairment of immune-related cells, but also to the aggressiveness of cancer cells themselves.

To verify our hypothesis, the association between TLR4 expression and cell proliferation was examined. However, this revealed that depletion of TLR4 expression slightly suppressed proliferation of BCa cell lines. Interestingly, however, depletion of TLR4 was found to dramatically promote the invasive ability of BCa cell lines, and that this was associated with a dramatic change in cell morphology. Subsequent microarray analysis revealed that the expression of many epithelial cell differentiation genes, including cytoskeletal-related keratin and SPRR genes, were significantly upregulated in TLR4 depleted cells.

More than 50 functional keratin genes have been identified, and it has been reported that keratin filaments are abundantly expressed in epithelial cells (18). The expression pattern of keratins differs between the various kinds of epithelial cells, but our microarray analysis revealed that it was squamous cell related keratin genes, such as KRT16 and KRT17 $(19,20)$, that were upregulated in TLR4 depleted cells. SPRRs on the other hand, encode a class of cornified envelope precursor proteins that are reported to have antioxidant potential and provide tissues with antioxidant barriers (21-23). It has been reported that these genes are upexpressed in squamous cell carcinoma (24) and may contribute to tumor progression through their essential role in wound healing and tissue remodeling following stress and injury (22). Taken together, the changes in keratin and SPRR expression suggest that TLR4 may affect cell morphology by regulating the expression of these squamous differentiationrelated genes.

As squamous differentiation is well-known as a poor prognosis factor in $\mathrm{BCa}(25,26)$, these results encouraged us to verify our findings using PrognoScan data. As expected, keratin and SPRR expression was significantly associated with poor prognosis of $\mathrm{BCa}$ patients in the cohort and inversely associated with the expression of TLR4. Furthermore, IHC staining in our cohort of clinical BCa specimens revealed that the expression of TLR4 disappeared in areas where squamous differentiation was observed. Taken together, our study suggests that low TLR4 expression may contribute to $\mathrm{BCa}$ aggressiveness by controlling cell differentiation.

A limitation of our study is that it did not clarify how TLR4 controls keratin, SPRR, or other cytoskeletal-related genes to regulate squamous differentiation in BCa. Further experiments are thus required to clarify these underlying mechanisms. 

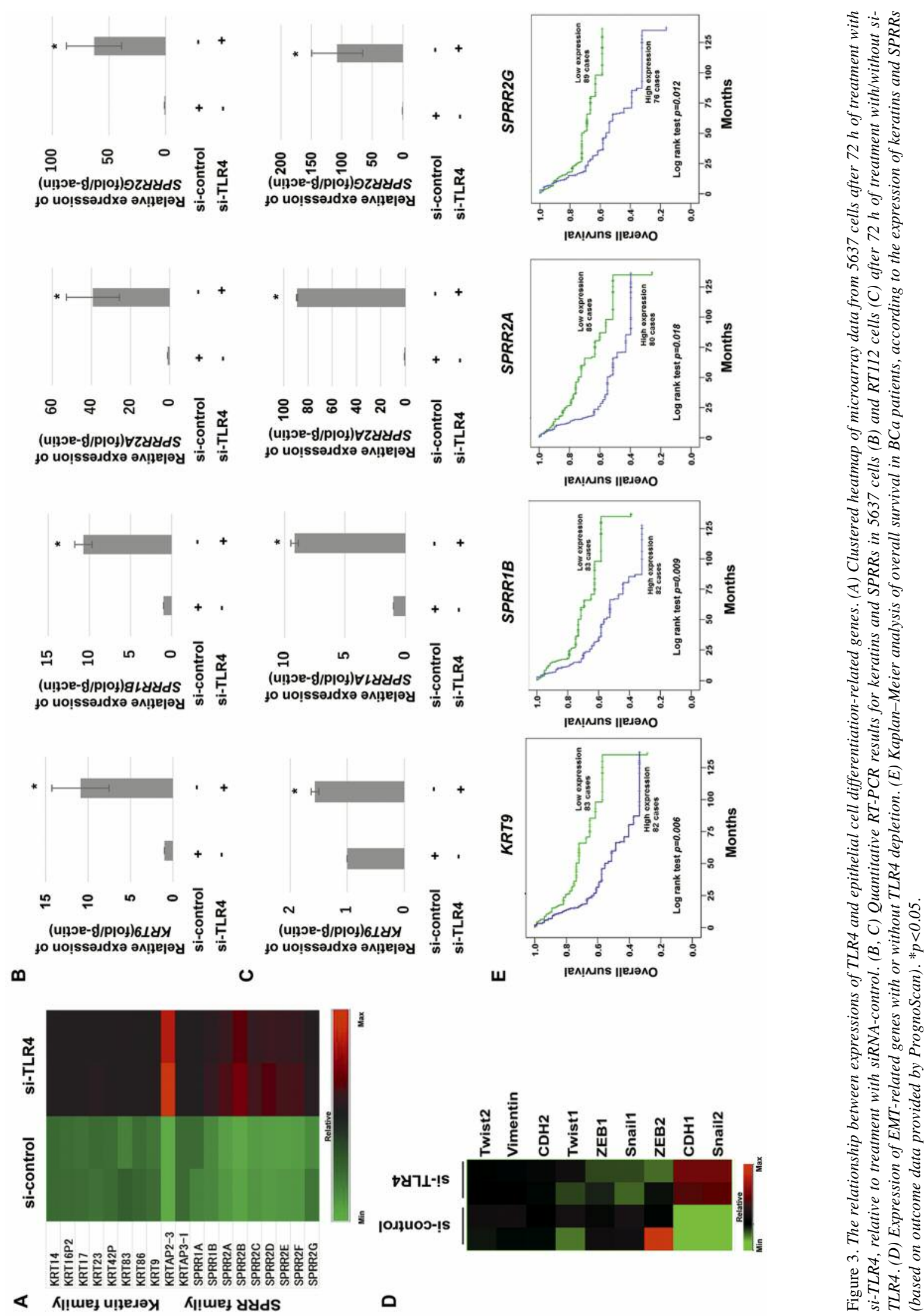
In conclusion, our study revealed that low TLR4 expression is significantly associated with BCa progression, and that TLR4 signaling may regulate invasiveness and differentiation of $\mathrm{BCa}$ cells through suppression of expression of keratin or SPRR.

\section{Conflicts of Interest}

The Authors have no financial relationships to disclose.

\section{Authors' Contributions}

Conception and design: Kusuhara Y, Daizumoto K, Fukawa T, Nakatsuji H; Acquisition of data: Kusuhara Y, Daizumoto K, Kawai K, Hirayama K, Shintani T, Dondoo TO, Ozaki K, Tsuda M, Fukuhara Y, Fukumori T, Takahashi M; Analysis and interpretation of data: Kowada M, Kusuhara Y, Daizumoto K; Writing and revision of the manuscript: Kusuhara Y, Daizumoto K, Fukawa T; Administrative, technical, or material support: Fukuhara Y; Study supervision: Kanayama H; Histological analysis: Bando $\mathrm{Y}$, Uehara $\mathrm{H}$.

\section{Acknowledgements}

The Authors wish to thank Ms. Yoshiko Shimada and Ms. Aya Shinomiya for their assistance with experiments and extend our special thanks to Mr. Hideaki Horikawa. We would also like to express our gratitude to the Graduate School of Tokushima University, Institute of Biomedical Sciences, Support center for Advanced Medical Science, for their technical support in microarray analysis.

\section{References}

1 Siegel RL, Miller KD and Jemal A: Cancer statistics, 2016. CA Cancer J Clin 66: 7-30, 2016. PMID: 26742998, DOI: $10.3322 /$ caac. 21332

2 Witjes JA, Comperat E, Cowan NC, De Santis M, Gakis G, Lebret T, Ribal MJ, Van der Heijden AD, Sherif A and European Association of Urology: EAU guidelines on muscle-invasive and metastatic bladder cancer: summary of the 2013 guidelines. Eur Urol 65: 778-792, 2014. PMID: 24373477, DOI: 10.1016/ j.eururo.2013.11.046

3 Sharma P, Shen Y, Wen S, Yamada S, Jungbluth AA, Gnjatic S, Bajorin DF, Reuter VE, Herr H, Old LJ and Sato E: CD8 tumorinfiltrating lymphocytes are predictive of survival in muscleinvasive urothelial carcinoma. Proc Natl Acad Sci USA 104: 39673972, 2007. PMID: 17360461, DOI: 10.1073/pnas.0611618104

4 Haabeth OA, Lorvik KB, Hammarstrom C, Donaldson IM, Haraldsen G, Bogen B and Corthay A: Inflammation driven by tumour-specific Th1 cells protects against B-cell cancer. Nat Commun 2: 240, 2011. PMID: 21407206, DOI: 10.1038/ ncomms 1239

$5 \mathrm{Yu} \mathrm{L}$ and Chen S: Toll-like receptors expressed in tumor cells: targets for therapy. Cancer Immunol Immunother 57: 1271-1278, 2008. PMID: 18256828, DOI: 10.1007/s00262-008-0459-8

6 C. Ayari C, Bergeron A, LaRue H, Menard C and Fradet Y: Tolllike receptors in normal and malignant human bladders. J Urol 185: 1915-1921, 2011. PMID: 21421234, DOI: 10.1016/ j.juro.2010.12.097
7 Aggarwal R, Misra S, Guleria C, Suri V, Mangat N, Sharma M, Nijhawan R and Minz R: Characterization of Toll-like receptor transcriptome in squamous cell carcinoma of cervix: A casecontrol study. Gynecol Oncol 138: 358-362, 2015. PMID: 26024767, DOI: 10.1016/j.ygyno.2015.05.029

8 Yang H, Zhou H, Feng P, Zhou X, Wen H, Xie X, Shen H and Zhu X: Reduced expression of Toll-like receptor 4 inhibits human breast cancer cells proliferation and inflammatory cytokines secretion. J Exp Clin Cancer Res 29: 92, 2010. PMID: 20618976, DOI: 10.1186/1756-9966-29-92

9 Chen $\mathrm{X}$, Zhao F, Zhang $\mathrm{H}$, Zhu $\mathrm{Y}, \mathrm{Wu} \mathrm{K}$ and Tan G: Significance of TLR4/MyD88 expression in breast cancer. Int J Clin Exp Pathol 8: 7034-7039, 2015. PMID: 26261595

10 Rakoff-Nahoum S and Medzhitov R: Toll-like receptors and cancer. Nat Rev Cancer 9: 57-63, 2009. PMID: 19052556, DOI: $10.1038 / \mathrm{nrc} 2541$

11 Olbert PJ, Kesch C, Henrici M, Subtil FS, Honacker A, Hegele A, Hofmann R and Hanze J: TLR4- and TLR9-dependent effects on cytokines, cell viability, and invasion in human bladder cancer cells. Urol Oncol 33: 110 e119-127, 2015. PMID: 25499923, DOI: 10.1016/j.urolonc.2014.09.016

12 Shintani T, Kusuhara Y, Daizumoto K, Dondoo TO, Yamamoto H, Mori H, Fukawa T, Nakatsuji H, Fukumori T, Takahashi M and Kanayama $\mathrm{H}$ : The involvement of hepatocyte growth factorMET-matrix metalloproteinase 1 signaling in bladder cancer invasiveness and proliferation. Effect of the MET inhibitor, Cabozantinib (XL184), on bladder cancer cells. Urology 101: 169.e167-169.e113, 2017. PMID: 28013036, DOI: 10.1016/j.urology.2016.12.006

13 Song J, Bishop BL, Li G, Duncan MJ and Abraham SN: TLR4initiated and cAMP-mediated abrogation of bacterial invasion of the bladder. Cell Host Microbe 1: 287-298, 2007. PMID: 17710226, DOI: 10.1016/j.chom.2007.05.007

14 Song J and Abraham SN: TLR-mediated immune responses in the urinary tract. Curr Opin Microbiol 11: 66-73, 2008. PMID: 18243043, DOI: 10.1016/j.mib.2007.12.001

15 Suhs KA, Marthaler BR, Welch RA and Hopkins WJ: Lack of association between the Tlr4 (Lpsd/Lpsd) genotype and increased susceptibility to Escherichia coli bladder infections in female C3H/HeJ mice. MBio 2: e00094-00011, 2011. PMID: 21628500, DOI: $10.1128 / \mathrm{mBio} .00094-11$

16 Smith NJ, VarleyCL, Eardley I, Feather S, Trejdosiewicz LK and Southgate J: Toll-like receptor responses of normal human urothelial cells to bacterial flagellin and lipopolysaccharide. J Urol 186: 1084-1092, 2011. PMID: 21784459, DOI: 10.1016/j.juro.2011.04.112

17 Shen Y, Bu M, Zhang A, Liu Y and Fu B: Toll-like receptor 4 gene polymorphism downregulates gene expression and involves in susceptibility to bladder cancer. Tumour Biol 36: 2779-2784, 2015. PMID: 25472584, DOI: 10.1007/s13277-014-2902-0

18 Moll R, Divo M and Langbein L: The human keratins: biology and pathology. Histochem Cell Biol 129: 705-733, 2008. PMID: 18461349, DOI: 10.1007/s00418-008-0435-6

19 Cao L, Zhou XD, Sens MA, Garrett SH, Zheng Y, Dunlevy JR, Sens DA and Somji S: Keratin 6 expression correlates to areas of squamous differentiation in multiple independent isolates of As(+3)-induced bladder cancer. J Appl Toxicol 30: 416-430, 2010. PMID: 20186695, DOI: 10.1002/jat.1513

20 KhanomR, Nguyen CT, Kayamori K, Zhao X, Morita K, Miki Y, Katsube K, Yamaguchi A and Sakamoto K: Keratin 17 is 
induced in oral cancer and facilitates tumor growth. PLoS One 11: e0161163, 2016. PMID: 27512993, DOI: 10.1371/ journal.pone. 0161163

21 Jackson B, Tilli CM, Hardman MJ, Avilion AA, MacLeod MC Ashcroft GS and Byrne C: Late cornified envelope family in differentiating epithelia - response to calcium and ultraviolet irradiation. J Invest Dermatol 124: 1062-1070, 2005. PMID: 15854049, DOI: 10.1111/j.0022-202X.2005.23699.x

22 Vermeij WP and Backendorf C: Skin cornification proteins provide global link between ROS detoxification and cell migration during wound healing. PLoS One 5: e11957, 2010. PMID: 20689819, DOI: 10.1371/journal.pone.0011957

23 Vermeij WP, Alia A and Backendorf C: ROS quenching potential of the epidermal cornified cell envelope. J Invest Dermatol 131: 1435-1441, 2011. PMID: 21248766, DOI: 10.1038/jid.2010.433

24 Zhang Y, Wang H, Wang J, Bao L, Wang L, Huo J and Wang X: Global analysis of chromosome 1 genes among patients with lung adenocarcinoma, squamous carcinoma, large-cell carcinoma, smallcell carcinoma, or non-cancer. Cancer Metastasis Rev 34: 249-264, 2015. PMID: 25937073, DOI: 10.1007/s10555-015-9558-0
25 Xylinas E, Rink M, Robinson BD, Lotan Y, Babjuk M, Brisuda A, Green DA, Kluth LA, Pycha A, Fradet Y, Faison T, Lee RK, Karakiewicz PI, Zerbib M, Scherr DS and Shariat SF: Impact of histological variants on oncological outcomes of patients with urothelial carcinoma of the bladder treated with radical cystectomy. Eur J Cancer 49: 1889-1897, 2013. PMID: 23466126, DOI: 10.1016/j.ejca.2013.02.001

26 Monn MF, Kaimakliotis HZ, PedrosaJA, Cary KC, Bihrle R, Cheng Land Koch MO: Contemporary bladder cancer: variant histology may be a significant driver of disease. Urol Oncol 33: 18 e15-18 e20, 2015. PMID: 25459358, DOI: 10.1016/j.urolonc.2014. 10.001
Received January 7, 2019

Revised January 20, 2019

Accepted January 22, 2019 